- Original Paper •

\title{
Different Impact of Central Pacific and Eastern Pacific EI Niño on the Duration of Sudden Stratospheric Warming
}

\author{
Yuanpu LI and Wenshou TIAN* \\ College of Atmospheric Science, Lanzhou University, Lanzhou 730000, China
}

(Received 23 November 2016; revised 13 February 2017; accepted 27 February 2017)

\begin{abstract}
The NCEP-NCAR reanalysis dataset and the HadISST dataset (1959-2014) are used to analyze the impact of two types of El Niño events, i.e., eastern Pacific El Niño (EP-El Niño) and central Pacific El Niño (CP-El Niño) events, on the duration of major and minor sudden stratospheric warmings (SSWs) in Northern Hemisphere winter (November to February). Although the frequency of major and minor SSWs during different types of El Niño shows no distinct differences, the duration of both major and minor SSWs during CP-El Niño is shorter than that during EP-El Niño. The spatial distribution of geopotential height anomalies preceding major SSWs resembles the western Pacific (WP) teleconnection pattern, while the spatial distribution of geopotential height anomalies preceding minor SSWs bears similarity to the Pacific-North America (PNA) teleconnection pattern. An enhancement of the strength of both wavenumber 1 and wavenumber 2 is found before major SSWs. Before minor SSWs, wavenumber 1 is also strengthened, but wavenumber 2 is weakened. The analysis also reveals that EP-El Niño tends to induce positive phases of PNA and WP teleconnections, while CP-El Niño induces negative-phase WP teleconnection. As the positive phases of the PNA and WP teleconnections are related to the strengthening of wavenumber 1, EP-El Niño causes an enhancement of wavenumber 1 in the high-latitude upper troposphere and an enhancement of the upward wave flux in the high-latitude stratosphere, accompanied by a negative anomaly in Eliassen-Palm flux divergence in the subpolar stratosphere, which accounts for the longer SSW duration during EP-El Niño than during CP-El Niño.
\end{abstract}

Key words: SSW, teleconnection, El Niño

Citation: Li, Y. P., and W. S. Tian, 2017: Different impact of central Pacific and eastern Pacific El Niño on the duration of sudden stratospheric warming. Adv. Atmos. Sci., 34(6), 771-782, doi: 10.1007/s00376-017-6286-0.

\section{Introduction}

Sudden stratospheric warmings (SSWs) are large-scale warmings of the polar stratosphere accompanied by a weakening of westerly wind around the polar vortex (Andrews et al., 1987). Following the dramatic breakdown or shift of the polar vortex, stratospheric anomalies sometimes propagate downwards into the troposphere and exert an impact on the weather of the troposphere on the weekly timescale (e.g., Baldwin and Dunkerton, 2001; Thompson and Wallace, 2001; Limpasuvan et al., 2004; Bell et al., 2009; Lu and Ding, 2015; Zhang et al., 2016), and the climate on the decadal timescale (e.g., Reichler et al., 2012). There are two kinds of SSWs - major and minor - and both are characterized by the reversal of the negative meridional temperature gradient $\left(60^{\circ}-90^{\circ} \mathrm{N}\right)$ at $10 \mathrm{hPa}$. The difference between the two is that major SSWs require a reversal of the westerly wind at $\left(60^{\circ} \mathrm{N}, 10 \mathrm{hPa}\right)$, while minor SSWs do not (e.g., Butler et al., 2015). Although minor SSWs also play an important role in affecting the troposphere (Wang and Chen, 2010), they are

\footnotetext{
* Corresponding author: Wenshou TIAN

Email: wstian@1zu.edu.cn
}

less documented in the literature than major SSWs.

A number of studies have revealed that ENSO-associated tropical sea surface temperature (SST) changes have significant impacts on the winter stratospheric polar vortex (e.g., Chen et al., 2003; Lan et al., 2012) and SSWs (e.g., Taguchi and Hartmann, 2006) in the Northern Hemisphere via modifying atmospheric teleconnections such as the western Pacific (WP) teleconnection (e.g. Horel and Wallace, 1981; Dai and Tan, 2016; Nakamura et al., 2016) and the PacificNorth America (PNA) teleconnection (Manzini et al., 2006; Garfinkel and Hartmann, 2008; Zhang et al., 2015). When the WP teleconnection is in its negative phase (characterized by an anticyclonic anomaly in the subpolar Pacific region), the stratospheric polar vortex has been found to be stronger (e.g., Nishii et al., 2010). However, Garfinkel and Hartmann (2008) argued that the stratospheric polar vortex tends to be weakened during positive-phase PNA teleconnection.

Two types of El Niño have been identified previously: the central Pacific El Niño (CP-El Niño), or El Niño Modoki (e.g., Larkin and Harrison, 2005; Ashok et al., 2007; Kao and Yu, 2009; Yu et al., 2010; Xie et al., 2014), and the eastern Pacific El Niño (EP-El Niño), or canonical El Niño. Different from EP-El Niño in which the largest positive SST anoma- 
lies are in the eastern Pacific, CP-El Niño is characterized by positive SST anomalies in the central Pacific, as shown in Fig. 1. Hegyi and Deng (2011) showed that the northern stratospheric polar vortex in winter is stronger during CP-El Niño than during EP-El Niño, since the Rossby wave train induced by CP-El Niño destructively interferes with the climatological extratropical wavenumber 1 . Xie et al. (2012) also found the polar vortex is strengthened as the upward planetary waves are weakened during the period of CP-El Niño. However, Graf and Zanchettin (2012) and Garfinkel et al. (2013) reported that both CP-El Niño and EP-El Niño induce a weakened stratospheric polar vortex in late winter. It is apparent from the above-mentioned studies that the responses of the northern stratospheric polar vortex to different types of El Niño events remain debatable.

Recently, Iza and Calvo (2015) found that SSWs play a significant role in explaining the different responses of the northern stratospheric polar vortex to the two types of El Niño events. In the absence of SSWs, the northern stratospheric polar vortex is weaker during EP-El Niño winter but stronger during CP-El Niño winter. In CP-El Niño winters with SSWs, the polar vortex appears to be weakened. However, there have been, so far, few works comparing the response of SSWs to CP-El Niño with that to EP-El Niño. Meanwhile, most previous studies have focused on the effect of El Niño events on the strength of the stratospheric polar vortex, while its impact on the duration of SSWs has rarely been examined. In the

(a)

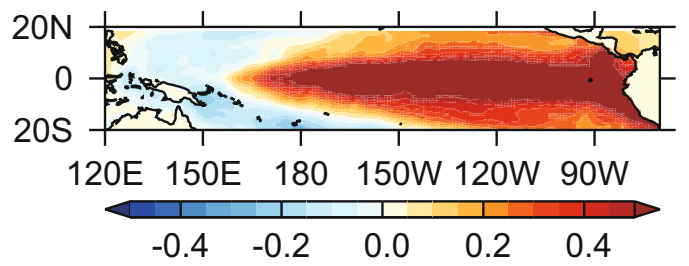

present study, the responses of SSWs in the Northern Hemisphere, including both major and minor SSWs, to CP-El Niño and EP-El Niño, are compared.

\section{Data and method}

Inspired by Ashok et al. (2007), EP-El Niño and CP-El Niño are investigated from the perspective of the two leading modes of the empirical orthogonal function analysis of the tropical Pacific SST anomalies from the Hadley Center HadISST dataset (Rayner et al., 2003), which has a $1^{\circ} \times 1^{\circ}$ horizontal resolution, over the period 1959-2014. The tropical Pacific is defined as the spatial domain covering $\left(20^{\circ} \mathrm{S}-\right.$ $\left.20^{\circ} \mathrm{N}, 120^{\circ} \mathrm{E}-60^{\circ} \mathrm{W}\right)$. The climatological monthly mean SST is removed from the raw data to obtain the anomalies of SST. The first two principal components are standardized and averaged over November to February to obtain two extended winter mean time series. These two time series are referred to as EPI and CPI, respectively. If EPI (CPI) is greater than 1 standard deviation, then the corresponding winter is classified as EP-El Niño (CP-El Niño). The selected EP-El Niño and CP-El Niño winters identified from this threshold are listed in Table 1. The regressions of SST anomalies onto the standardized EPI and CPI are shown in Fig. 1 to demonstrate the pattern of SST anomalies corresponding to EP-El Niño and CP-El Niño events.

The onset date of SSWs is defined following the method

(b)

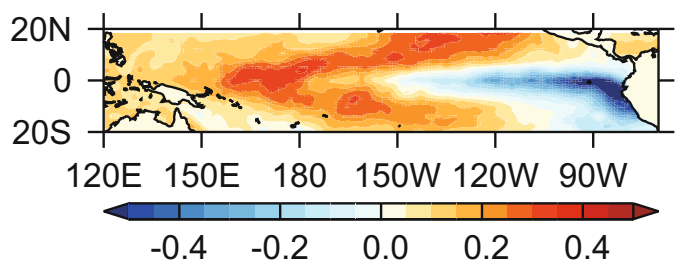

Fig. 1. Regression maps of SST anomalies (units: ${ }^{\circ} \mathrm{C}$ ) onto the standardized (a) EPI and (b) CPI time series from 1959 to 2014 based on the HadISST dataset.

Table 1. The onset dates (year/month/day) of major SSWs and minor SSWs occurring in EP-El Niño and CP-El Niño winters during the period 1959-2014. EP-El Niño and CP-El Niño winters are identified when the winter mean EPI and CPI are above 1 standard deviation (see text for details of the definition of the EPI and CPI, as well as the definition of the date of SSW onset).

\begin{tabular}{|c|c|c|c|c|c|}
\hline CP-El Niño & Major SSW & Minor SSW & EP-El Niño & Major SSW & Minor SSW \\
\hline $1968 / 1969$ & $1968 / 11 / 28$ & $\begin{array}{c}\text { 1968/11/12; } \\
\text { 1969/2/2 }\end{array}$ & $1965 / 1966$ & $\begin{array}{c}1965 / 12 / 8 \\
1966 / 2 / 24\end{array}$ & - \\
\hline $1987 / 1988$ & $1987 / 12 / 8$ & $1988 / 2 / 29$ & $1972 / 1973$ & $1973 / 2 / 2$ & $1972 / 11 / 24$ \\
\hline 1990/1991 & - & $\begin{array}{c}1990 / 12 / 14 \\
1991 / 1 / 20\end{array}$ & $1982 / 1983$ & - & $\begin{array}{c}1982 / 12 / 31 \\
1983 / 1 / 27\end{array}$ \\
\hline $1993 / 1994$ & - & $1993 / 12 / 30$ & 1986/1987 & $1987 / 1 / 23$ & $1987 / 1 / 3$ \\
\hline 1995/1996 & - & $1996 / 1 / 31$ & $1987 / 1988$ & $1987 / 12 / 8$ & $1988 / 2 / 29$ \\
\hline $2001 / 2002$ & $2002 / 1 / 2$ & $2001 / 12 / 23$ & $1991 / 1992$ & - & $1992 / 1 / 11$ \\
\hline $2004 / 2005$ & - & $2005 / 2 / 2$ & $1994 / 1995$ & - & $1995 / 1 / 24$ \\
\hline $2009 / 2010$ & $2010 / 2 / 9$ & $2010 / 1 / 21$ & $1997 / 1998$ & - & $\begin{array}{c}1997 / 12 / 8 \\
1998 / 2 / 2\end{array}$ \\
\hline $2012 / 2013$ & $2013 / 1 / 7$ & $2012 / 12 / 6$ & $2002 / 2003$ & $2003 / 1 / 18$ & $2002 / 12 / 29$ \\
\hline $2014 / 2015$ & - & $2014 / 12 / 31$ & $2009 / 2010$ & $2010 / 2 / 9$ & $2010 / 1 / 21$ \\
\hline
\end{tabular}


of Charlton and Polvani (2007). A major SSW is recognized to occur when the $10 \mathrm{hPa}$ zonal mean zonal wind at $60^{\circ} \mathrm{N}$ turns to easterly wind, while a minor SSW is recognized to occur when the meridional temperature gradient between $60^{\circ} \mathrm{N}$ and $90^{\circ} \mathrm{N}$ at $10 \mathrm{hPa}$ becomes positive. The definition of minor SSWs in terms of the temperature gradient is close to the standard WMO definition for minor SSWs (e.g., Butler et al., 2015). The onset dates are constrained in November to February and a 20-day interval of westerly wind or negative temperature gradient is required before the next onset date of major SSW or minor SSW can be defined. The selected major and minor SSW events occurring in EP-El Niño and CP-El Niño winters are listed in Table 1. The duration of major SSWs is defined as the number of days when the $10 \mathrm{hPa}$ zonal mean zonal wind at $60^{\circ} \mathrm{N}$ becomes easterly, while the duration of minor SSWs is defined as the number of days when the meridional temperature gradient between $60^{\circ} \mathrm{N}$ and $90^{\circ} \mathrm{N}$ at $10 \mathrm{hPa}$ becomes positive in the extended winter defined as November to February. The meteorological fields analyzed are from the National Centers for Environmental Prediction-National Center for Atmospheric Research (NCEP-NCAR) reanalysis dataset, which has a horizontal resolution of $2.5^{\circ} \times 2.5^{\circ}$ and covers the period from 1959 to 2014. The interpolated outgoing longwave radiation (OLR) data (Liebmann and Smith, 1996) from the National Oceanic Atmospheric Administration (NOAA), with a horizontal resolution of $2.5^{\circ} \times 2.5^{\circ}$ and covering the period from 1974 to 2013, are also analyzed.

The daily indices of the PNA and WP teleconnections, denoted as $I_{\mathrm{PNA}}$ and $I_{\mathrm{WP}}$, are from the NOAA Climate Prediction Center, which are calculated using the centers-of-action method based on the $500 \mathrm{hPa}$ geopotential height (GH) field, denoted as $Z$, as used by Wallace and Gutzler (1981):

$$
\begin{aligned}
I_{\mathrm{PNA}}= & {\left[Z_{\left(15^{\circ}-25^{\circ} \mathrm{N}, 180^{\circ}-140^{\circ} \mathrm{W}\right)}-Z_{\left(40^{\circ}-50^{\circ} \mathrm{N}, 180^{\circ}-140^{\circ} \mathrm{W}\right)}+\right.} \\
& \left.Z_{\left(45^{\circ}-60^{\circ} \mathrm{N}, 125^{\circ}-105^{\circ} \mathrm{W}\right)}-Z_{\left(25^{\circ}-35^{\circ} \mathrm{N}, 90^{\circ}-70^{\circ} \mathrm{W}\right)}\right] ; \\
I_{\mathrm{WP}}= & {\left[Z_{\left(25^{\circ}-40^{\circ} \mathrm{N}, 140^{\circ} \mathrm{E}-150^{\circ} \mathrm{W}\right)}-Z_{\left(50^{\circ}-70^{\circ} \mathrm{N}, 140^{\circ} \mathrm{E}-150^{\circ} \mathrm{W}\right)}\right] . }
\end{aligned}
$$

To diagnose the strength of the planetary wave, the EliassenPalm flux is calculated in log-pressure coordinates using the method given by Andrews et al. (1987):

$$
\begin{aligned}
& F_{\phi}=\rho a \cos \phi\left(\frac{\overline{v^{\prime} \theta^{\prime}}}{\bar{\theta}_{z}} \bar{u}_{z}-\overline{v^{\prime} u^{\prime}}\right) ; \\
& F_{z}=\rho a \cos \phi\left[\left(f-\frac{1}{a \cos \phi}(\bar{u} \cos \phi)_{\phi}\right) \frac{\overline{v^{\prime} \theta^{\prime}}}{\bar{\theta}_{z}}-\overline{w^{\prime} u^{\prime}}\right] .
\end{aligned}
$$

The divergence of Eliassen-Palm flux is defined as

$$
\boldsymbol{\nabla} \cdot \boldsymbol{F}=\frac{1}{a \cos \phi} \frac{\partial}{\partial \phi}\left(F_{\phi} \cos \phi\right)+\frac{\partial}{\partial z} F_{z},
$$

where $a$ is the mean of Earth's radius, $u, v$ and $w$ are the zonal, meridional and vertical wind components, $\theta$ is potential temperature, $z$ is the height in the log-pressure coordinate, $\phi$ is latitude, $H$ is the mean scale height of the atmosphere, $f$ is the Coriolis parameter, $\rho=\rho_{\mathrm{S}} \exp (-z / H)$ is the standard air density in log-pressure coordinates, and $\rho_{s}$ is the reference air density at sea level. The overbar denotes the zonal mean, and the prime symbol denotes departures from the zonal mean.

The correlation between prominent components of the SST field and atmospheric variables, such as GH and OLR, are measured by the Pearson coefficient. The significance test for correlation is the two-tailed Student's $t$-test, employing the effective number of degrees of freedom $\left(N_{\text {eff }}\right)$ for the auto-correlated time series (Bretherton et al., 1999). The $N_{\text {eff }}$ is defined as follows (Li et al., 2012):

$$
\frac{1}{N_{\mathrm{eff}}} \approx \frac{1}{N}+\frac{2}{N} \sum_{j=1}^{N} \frac{N-j}{N} \rho_{X X}(j) \rho_{Y Y}(j),
$$

where $N$ is the sample size and $\rho_{X X}\left(\rho_{Y Y}\right)$ represents the autocorrelation coefficients of the time series of $X(Y)$ at time lag $j$.

The two-tailed Kolmogorov-Smirnov (KS) test is used in this study to test whether the probability distribution functions (PDFs) of two samples are significantly different from each other, and the corresponding results shown in the following analysis are significant at the $99 \%$ confidence level unless otherwise stated.

\section{Results}

According to Table 1, the frequency of major SSWs during EP-El Niño and CP-El Niño is 0.7 and 0.5 events per year, respectively. The frequency of minor SSWs during EPEl Niño and CP-El Niño is 1.3 and 1.4 events per year. The differences in the frequencies of major and minor SSWs between EP-El Niño and CP-El Niño are not statistically significant. The average frequency of major and minor SSWs for the period 1959-2014 is 0.5 per year and 1.4 events per year, respectively, which are also not significantly different from those during EP-El Niño and CP-El Niño.

Before proceeding further, it is worthwhile clarifying the relationship between SSW strength and duration. In each major SSW case, there may be several periods in which the zonal winds of $60^{\circ} \mathrm{N}$ at $10 \mathrm{hPa}$ are easterlies. In each minor SSW case, there may be several periods in which the meridional temperature gradient between $60^{\circ} \mathrm{N}$ and $90^{\circ} \mathrm{N}$ at $10 \mathrm{hPa}$ is positive. The maximum easterly wind and the maximum positive temperature gradient represent the strength of major and minor SSWs, respectively. Figure 2a is a scatter diagram of the duration of the easterly wind versus the maximum easterly wind during an easterly wind period. It can be seen that the duration of easterly wind increases almost linearly with the maximum strength of the easterly wind, i.e., the duration of major SSWs is, to a large extent, proportional to the strength of major SSWs. Figure $2 b$ is a scatter diagram of the duration of positive meridional temperature gradient versus the maximum of the temperature gradient. It is apparent that the duration of minor SSWs also increases with the strength of minor SSWs as the duration of positive meridional temperature gradient increases with the maximum meridional temperature gradient, although the linearity between them is less 
(a)

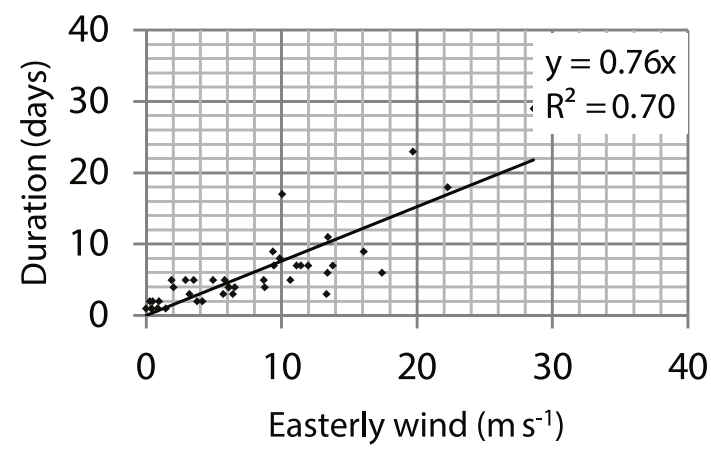

(b)

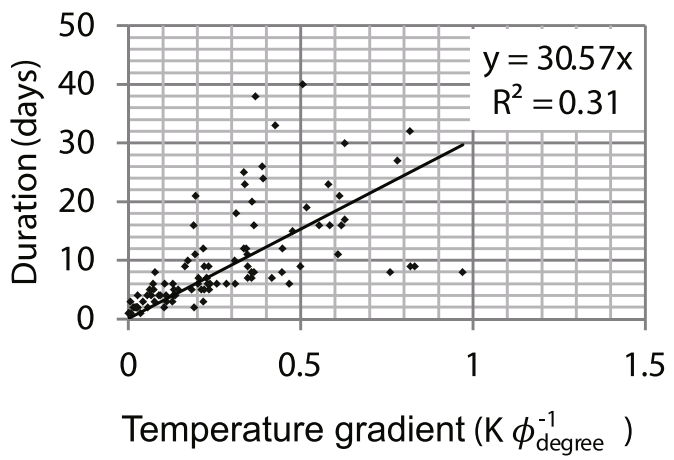

Fig. 2. (a) Scatter diagram of the duration of zonal mean easterly wind at $\left(60^{\circ} \mathrm{N}, 10 \mathrm{hPa}\right)$ (units: d) versus the maximum easterly wind (units: $\mathrm{m} \mathrm{s}^{-1}$ ) in a continual period of easterly wind. (b) Scatter diagram of the duration of positive meridional temperature gradient $\left(60^{\circ}-90^{\circ} \mathrm{N}\right)$ at $10 \mathrm{hPa}$ versus the maximum meridional temperature gradient (units: $\mathrm{K} \phi_{\text {degree }}^{-1}$ ) in a continual period of positive meridional temperature gradient.

justified, i.e., for a given minor SSW strength, some minor SSWs last longer while some others have a shorter duration. Figure 2 indicates that, on average, a stronger SSW tends to have a longer duration. Nevertheless, for the purpose of understanding the dynamical coupling between the troposphere and the stratosphere, the duration of SSWs is more instructive, as polar stratospheric anomalies are more likely to get into the troposphere during a longer SSW event.

Figure 3 shows the means of the SSW duration during EP-El Niño and CP-El Niño derived from the reanalysis data. The duration of major SSWs during CP-El Niño is equal to the climatological mean duration, while the duration of major SSWs during EP-El Niño is longer than the climatological mean duration (Fig. 3a). Although the duration of major SSWs during EP-El Niño is longer than that during CP-El Niño, the statistical significance of the difference does not reach the $95 \%$ confidence level under the Student's $t$-test. The duration of minor SSWs during CP-El Niño is shorter than its climatological mean, while the duration of minor SSWs during EP-El Niño is longer than the climatological mean. The statistical significance of the difference in minor SSW duration between CP-El Niño and EP-El Niño reaches the $95 \%$ confidence level under the Student's $t$-test (Fig. 3b). It should be pointed out that the differences in the frequency of minor or major SSWs between CP-El Niño and EP-El Niño are statistically insignificant, although significant differences exist in the duration of these events between CP-El Niño and EPEl Niño. In the definition of the frequency of SSWs, a 20-day interval of westerly wind or negative temperature gradient is required before the next onset date of a major SSW or a minor SSW can be defined. This 20-day interval criterion for determining the frequency of SSWs makes the differences in the frequency of minor or major SSWs between CP-El Niño and EP-El Niño indistinct.

To investigate the difference in the $\mathrm{GH}$ anomalies prior to minor and major SSWs, Fig. 4 shows the composited 200 $\mathrm{hPa} \mathrm{GH}$ anomalies 5-10 days prior to minor and major SSWs derived from the NCEP-NCAR reanalysis dataset. It is apparent that the height anomalies preceding minor SSWs are different from those preceding major SSWs, both in their magnitude and spatial distribution. At middle and high latitudes, negative GH anomalies exist over the North Pacific and positive height anomalies over Northeast Canada (Fig. 4 a), which bear a resemblance to the positive phase of the PNA teleconnection (Fig. 5a). The height anomalies preceding major SSWs (Fig. 4d) are characterized by positive height anomalies over the subtropical western Pacific and negative height anomalies over North Russia, which resemble the positive phase of the WP teleconnection (Fig. 5b). The magnitude of the height anomalies at high latitudes preceding major SSWs is larger than that preceding minor SSWs. Garfinkel et al. (2012) and Dai and Tan (2016) also discussed the height anomalies preceding major SSWs, and their result is consistent with that in Fig. 4d. However, our analysis further reveals that height anomalies preceding minor SSWs are different from those preceding major SSWs, especially in their connections to teleconnections.

Also shown in Fig. 4 are the wavenumber 1 and 2 components of $200 \mathrm{hPa}$ height anomalies prior to minor and major SSWs. The negative center of wavenumber 1 height anomalies preceding minor SSWs (Fig. 4b) is located from the North Pacific to Northeast Asia, and the positive center is located from Northeast Canada to the North Atlantic, which coincides with the climatological wavenumber 1 pattern at $200 \mathrm{hPa}$, implying a strengthening of wavenumber 1 in the upper troposphere. The wavenumber 1 component of height anomalies preceding major SSWs (Fig. 4e) also coincides with the climatological wavenumber 1 pattern, but the strength of wavenumber 1 anomalies preceding major SSWs is twice as strong as that preceding minor SSWs. The two negative centers of the wavenumber 2 anomalies preceding minor SSWs (Fig. 4c) are located over Europe and the North Pacific, and the two positive centers are located over Northeast Canada and Northeast Asia, which are nearly $180^{\circ}$ out 
(a)

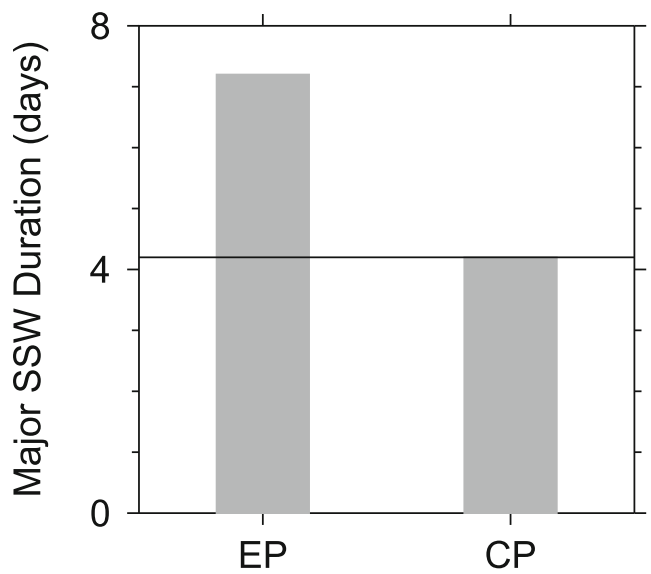

(b)

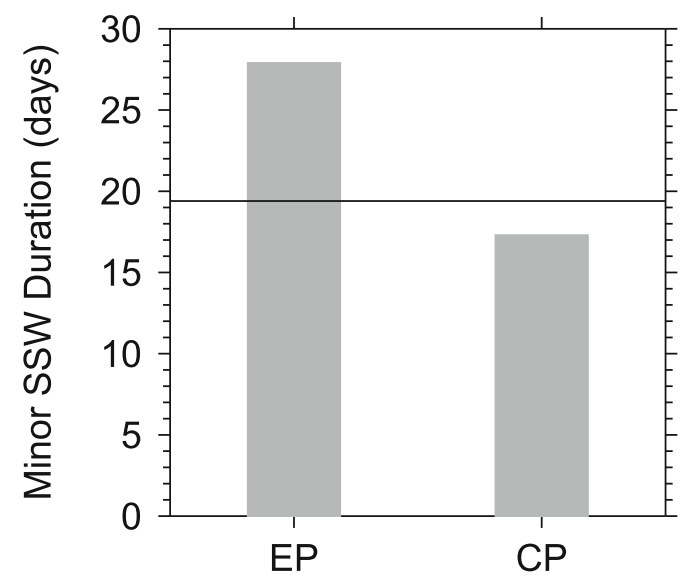

Fig. 3. The means of (a) major SSW duration and (b) minor SSW duration (units: d) during EP-El Niño and CP-El Niño winters, as listed in Table 1. The duration of SSWs is derived from the NCEP-NCAR reanalysis data. The black horizontal lines in (a) and (b) represent the climatological means of the duration of major SSWs and minor SSWs.

(a)
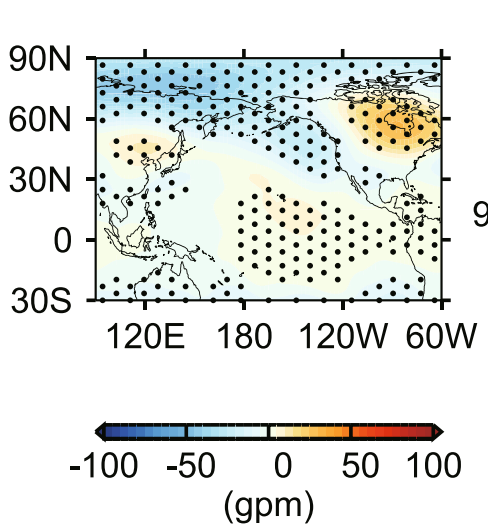

(d)

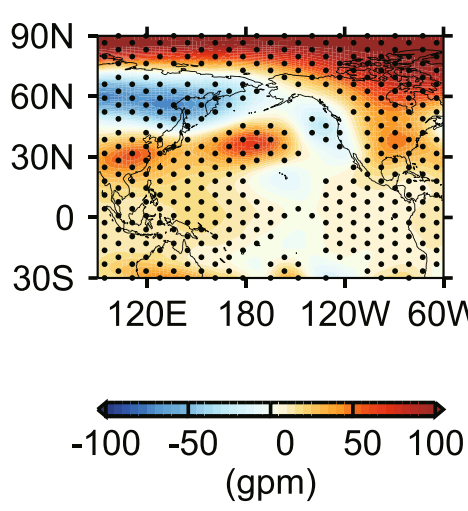

(b)

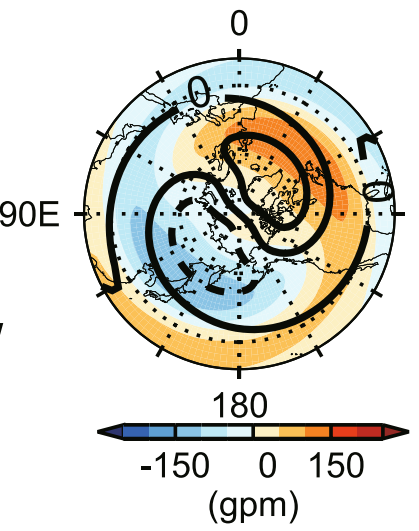

(e)

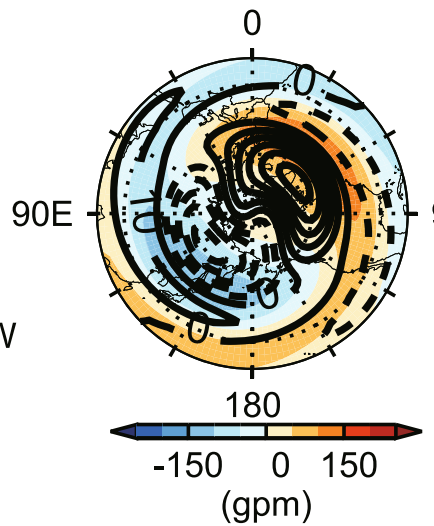

(c)

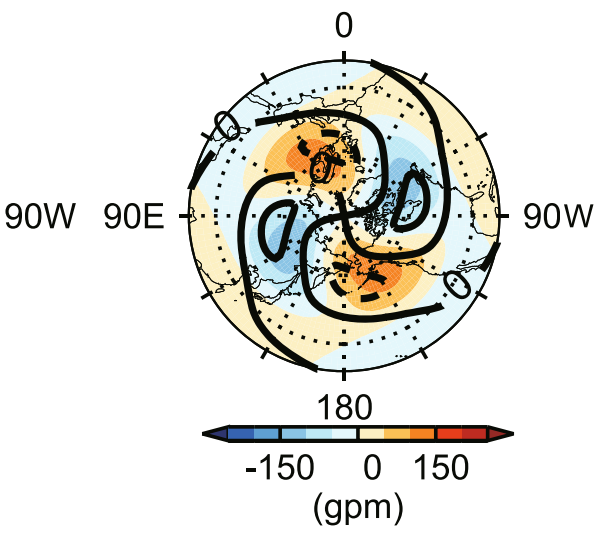

(f)

Fig. 4. Composited $200 \mathrm{hPa}$ GH anomalies (units: gpm) 5-10 days prior to (a) minor SSWs and (d) major SSWs, derived from the NCEP-NCAR reanalysis dataset. The anomalies over dotted regions are statistically significant above the $99 \%$ confidence level according to the Student's $t$-test. (b, e) Wavenumber-1 and (c, f) wavenumber-2 components of $200 \mathrm{hPa}$ height anomalies preceding (b, c) minor SSWs and (e, f) major SSWs, shown by contours (contour intervals: $\pm 10, \pm 20, \pm 30 \mathrm{gpm}$ ). The color-filled contours in (b, e) represent the climatology of wavenumber 1 and the color-filled contours in (c, f) represent the climatology of wavenumber 2. 
(a)

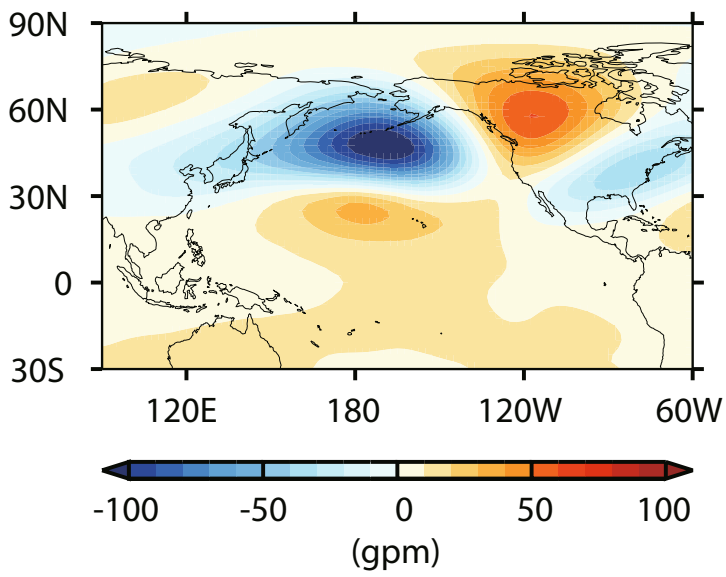

(c)

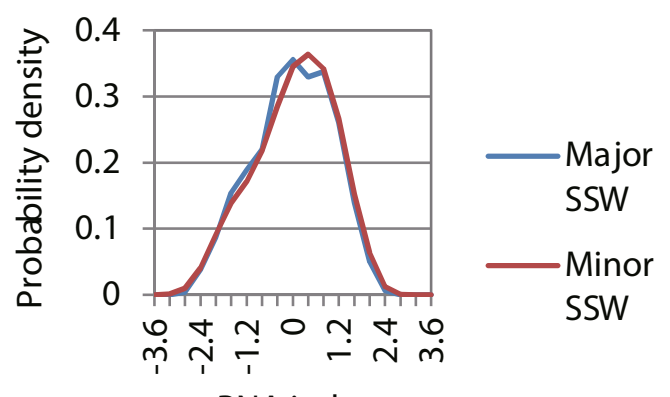

PNA index (b)

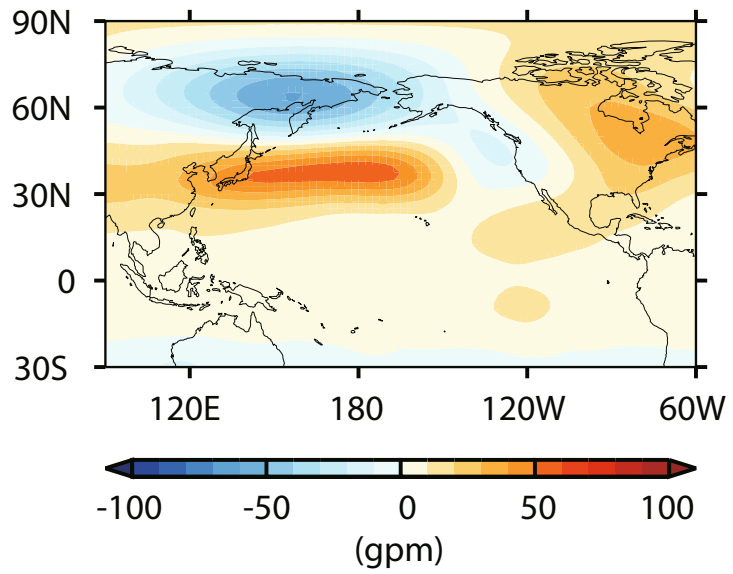

(d)

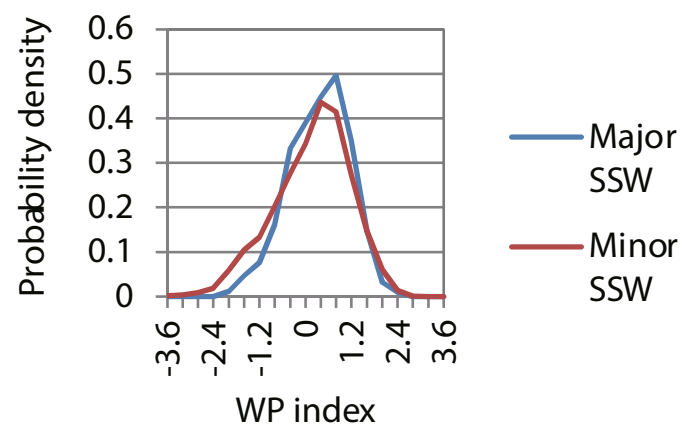

Fig. 5. Regressions of the standardized (a) PNA and (b) WP index onto GH at $200 \mathrm{hPa}$ in winter, and the PDFs of the (c) PNA and (d) WP indices 5-10 days prior to major SSWs and minor SSWs.

of phase with the climatological wavenumber 2, implying a weakening of wavenumber 2 in the upper troposphere. However, the wavenumber 2 anomalies preceding major SSWs (Fig. 4f) almost coincide with the wavenumber 2 climatology, resulting in a strengthening of wavenumber 2 in the upper troposphere.

The patterns of the positive phases of the PNA and WP teleconnections and the PDFs of the PNA and WP indices 510 days prior to major SSWs and minor SSWs are shown in Fig. 5. The PDFs of the PNA index before major and minor SSWs are not significantly different (Fig. 5c). However the PDFs of the WP index before major and minor SSWs are significantly different, i.e., there are more positive phases and fewer negative phases of the WP teleconnection before major SSWs (Fig. 5d). Thus, a positive phase of the WP teleconnection is more favorable for the occurrence of major SSWs. A careful examination of Figs. 5c and d reveals a tendency for more positive phases of the PNA and WP teleconnections before minor SSWs, although this feature is not prominent.

To further verify that the duration of major and minor SSWs is linked to teleconnections, the precursors in the GH field for long- and short-lasting SSWs are analyzed. Figures $6 \mathrm{a}$ and $\mathrm{b}$ show the composited $200 \mathrm{hPa}$ GH anomalies 5-10 days prior to short-lasting ( $<5$ days) and long-lasting $(>15$ days) minor SSWs. Overall, the height anomalies preceding short-lasting and long-lasting minor SSWs have a similar pattern to that in Fig. 4a, with a resemblance to the positive phase of the PNA teleconnection. Figures $6 c$ and d further show the PDFs of the PNA and WP indices 5-10 days prior to short-lasting and long-lasting minor SSWs. It can be seen that minor SSWs tend to last longer if there are more positive phases of the PNA and WP teleconnections preceding the warming. Figures $7 \mathrm{a}$ and $\mathrm{b}$ show the composited 200 $\mathrm{hPa} \mathrm{GH}$ anomalies 5-10 days prior to short-lasting and longlasting major SSWs. The spatial distributions of the height anomalies in Figs. 7a and b are also similar to that in Fig. 4d, which resembles the positive phase of the WP teleconnection. The PDFs of the PNA and WP indices 5-10 days prior to short-lasting and long-lasting major SSWs (Figs. 7c and d) further indicate that long-lasting major SSWs correspond to more positive phases of the PNA and WP teleconnections preceding the warming.

The above analysis suggests that the duration of SSWs is closely related to the PNA and WP teleconnections. In the following analysis, the linkage between these teleconnections and El Niño events is discussed in more detail. In 
(a)

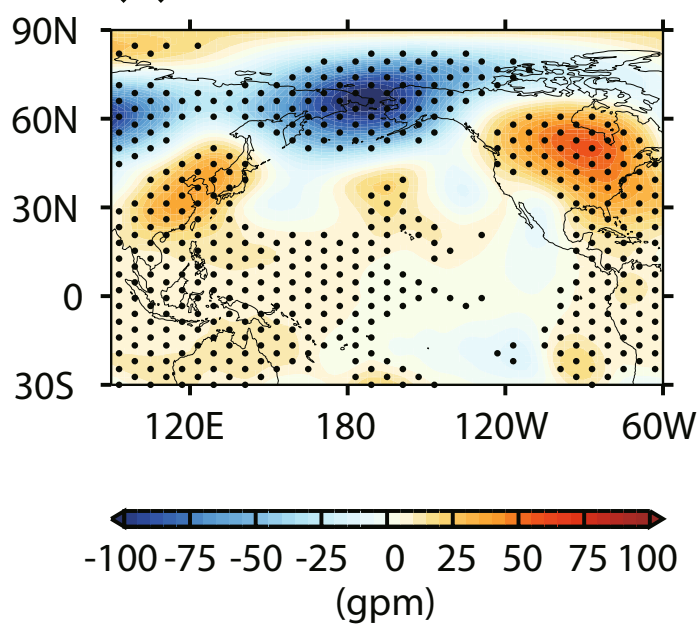

(c)

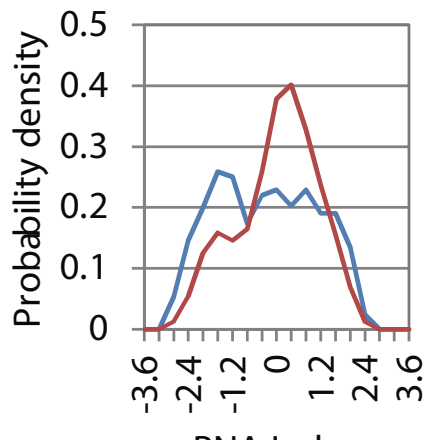

PNA Index (b)

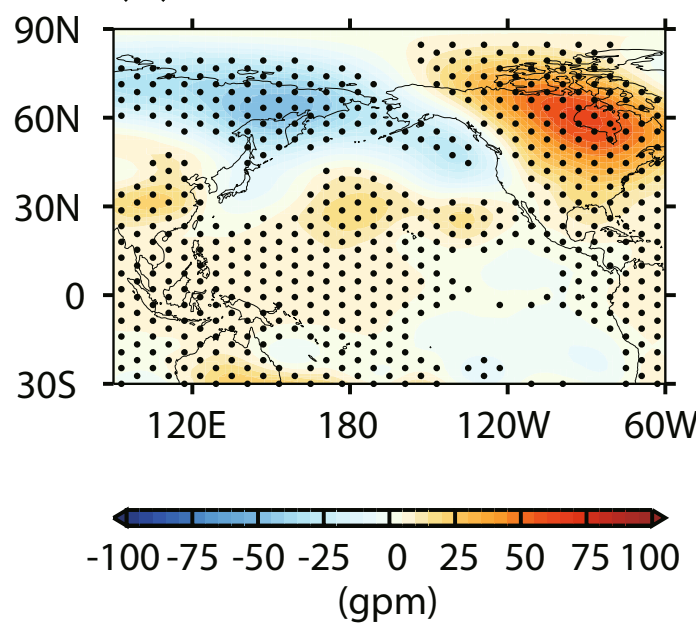

(d)

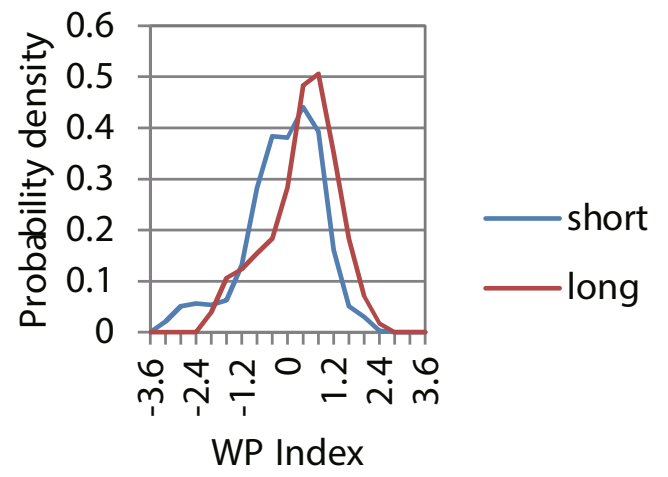

Fig. 6. Composited $200 \mathrm{hPa} \mathrm{GH}$ anomalies (units: gpm) 5-10 days prior to (a) short-lasting and (b) long-lasting minor SSWs derived from the NCEP-NCAR reanalysis dataset. The threshold for long-lasting and short-lasting minor SSWs is 15 and 5 days, respectively. The anomalies over dotted regions are statistically significant above the 99\% confidence level according to the Student's $t$-test. (c, d) The PDFs of the (c) PNA and (d) WP indices 5-10 days prior to short-lasting and long-lasting minor SSWs.

general, the positive SST anomalies in the tropics associated with El Niño will enhance convective activity and change the tropical height field by releasing latent heat, and then further affect the height field at higher latitudes through teleconnections. Figure 8 shows the correlation between the principle components of the SST anomalies in the tropical Pacific and the winter mean OLR from 1974 to 2012 . We can see from Fig. 8a that statistically significant negative correlations exist near the dateline between the EPI and winter mean OLR, implying enhanced convection there when the EPI is in its positive phase. The result here is consistent with that reported in Chiodi and Harrison (2013). By contrast, statistically significant negative correlations exist to the west of the dateline between the CPI and winter mean OLR, implying enhanced convection there when the CPI is in its positive phase.

Figures $9 \mathrm{a}$ and $\mathrm{b}$ show the composited $200 \mathrm{hPa} \mathrm{GH}$ anomalies in the Pacific region during EP-El Niño and during CP-El Niño. It is evident that there are statistically significant $200 \mathrm{hPa}$ GH anomalies over the tropical eastern Pa- cific during EP-El Niño (Fig. 9a). During CP-El Niño, statistically significant $200 \mathrm{hPa}$ height anomalies are apparent over the tropical western Pacific. The locations of these significant height anomalies in Figs. 9a and b coincide with the significant OLR anomalies in Figs. $8 \mathrm{a}$ and b. At high latitudes, the spatial pattern of $200 \mathrm{hPa}$ height anomalies to the east of the dateline during EP-El Niño shows a resemblance to the positive phase of the PNA teleconnection (Fig. 9a). During CP-El Niño, the extratropical $200 \mathrm{hPa}$ GH has positive anomalies north of the Aleutian Islands and negative anomalies over Japan to the middle Pacific, which resembles the negative phase of the WP teleconnection (Fig. 9b). A positive phase of the PNA teleconnection is favorable for longer minor and major SSWs, as suggested in Figs. 6c and 7c. However, a negative phase of the WP teleconnection is not conducive to longer minor and major SSWs, as suggested in Figs. $6 \mathrm{~d}$ and $7 \mathrm{~d}$. Note that the height anomalies at middle and high latitudes in Fig. 9b are statistically insignificant over most regions, possibly due to the relatively small sample 
(a)

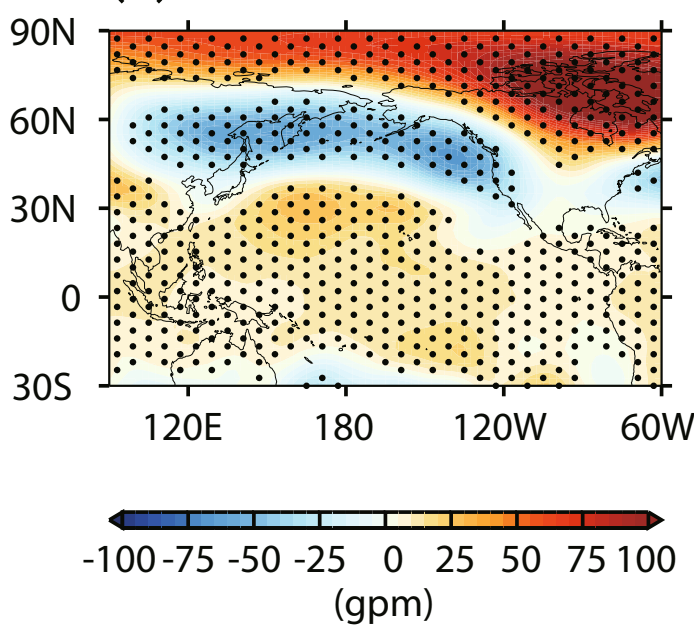

(c)

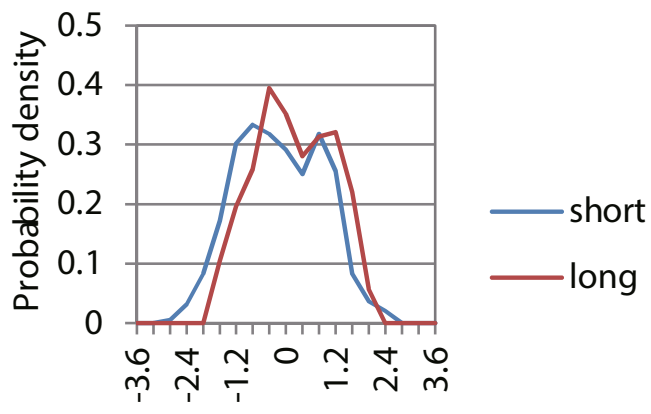

PNA Index (b)

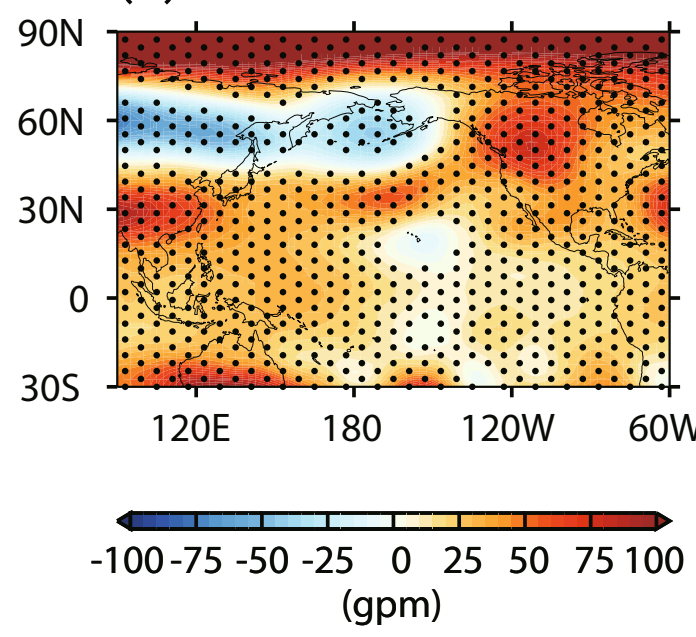

(d)

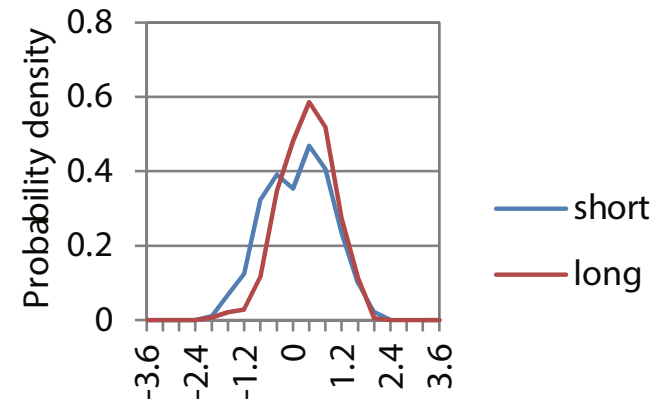

WP Index

Fig. 7. As in Fig. 6, but for (a) short-lasting and (b) long-lasting major SSWs, and the PDFs of the (c) PNA and (d) WP indices 5-10 days prior to short-lasting and long-lasting major SSWs.

(a)

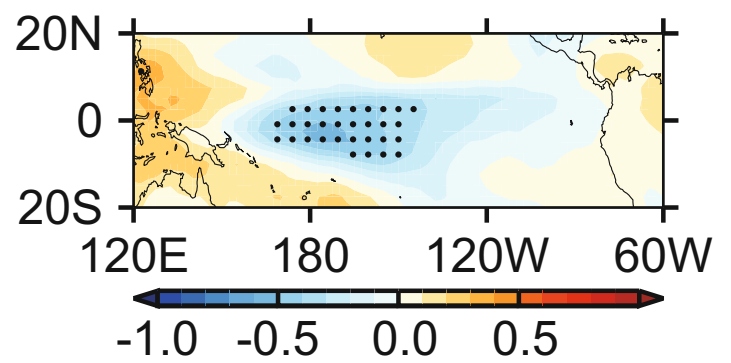

(b)

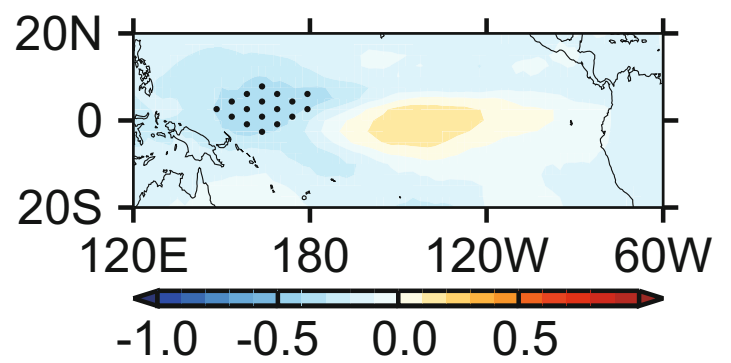

Fig. 8. Correlation coefficients between the winter mean of the principle components of SST anomalies in the tropical Pacific and the winter mean OLR from 1974 to 2012, (a) for the EPI and (b) for CPI. The regions with black spots represent the correlation exceeding the $95 \%$ confidence level under the Student's $t$-test.

sizes of EP-El Niño and CP-El Niño events. Figures 9c and d further show the correlation between $\mathrm{GH}$ anomalies over the Pacific region and the principle components of the tropical Pacific SST anomalies. We can see that the correlations in Figs. 9c and d have similar spatial patterns to those in Figs. $9 \mathrm{a}$ and $\mathrm{b}$, but have more regions with statistically significant correlations.
As mentioned above, the height anomalies preceding minor SSWs have a similar spatial pattern to the positive phase of the PNA teleconnection, and the height anomalies preceding major SSW bear a similarity with the positive phase of the WP teleconnection. Therefore, it is necessary to further examine the linkages between the two kinds of El Niño and teleconnections. The PDFs of the PNA and WP indices for the 
(a)
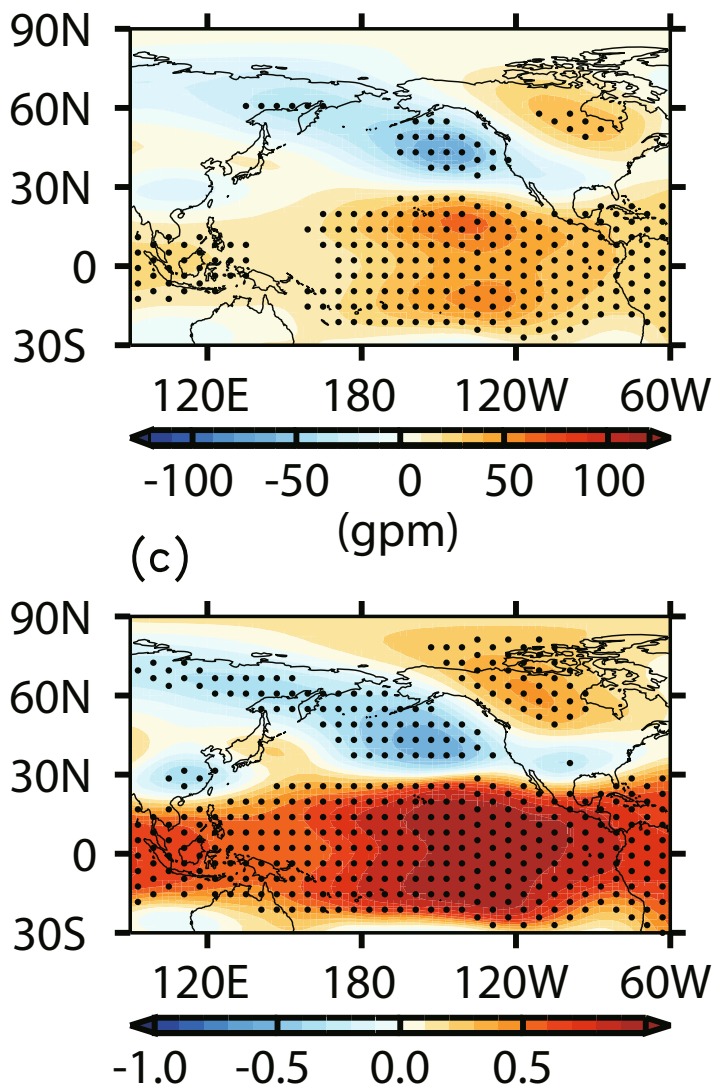

(b)
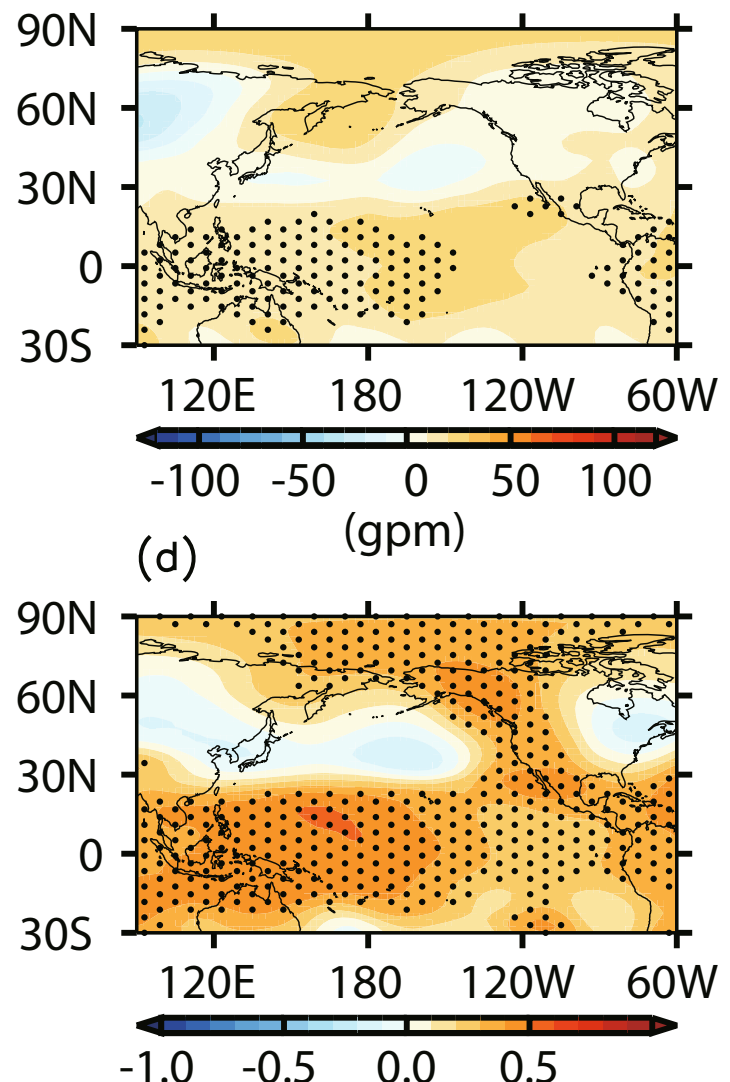

Fig. 9. Composited GH anomalies (defined as the departure from its climatology) at 200 hPa over the Pacific region during (a) EP-El Niño and (b) CP-El Niño. (c, d) Correlation coefficients between the winter mean of the principle components of SST anomalies in the tropical Pacific and the winter mean of GH from 1959 to 2013, (c) for the EPI and (d) for the CPI. The regions with black spots represent anomalies and correlations exceeding the $95 \%$ confidence level under the Student's $t$-test.

winter season (November-February) during EP-El Niño and CP-El Niño are shown in Figs. 10a and b, respectively, and the climatological PDFs of the PNA and WP indices are also shown for reference. Figure 10a indicates that EP-El Niño is favorable for the occurrence of positive phases of the PNA teleconnection, i.e., there are more positive phases than negative phases of the PNA teleconnection during EP-El Niño. By contrast, the PDF of the PNA teleconnection during CPEl Niño events is nearly the same as the climatological PDF of the PNA teleconnection. The KS test also indicates that the climatological PDFs of the PNA index have no significant differences from those during CP-El Niño. Figure 10b indicates that EP-El Niño is favorable for the occurrence of positive phases of the WP teleconnection, i.e., there are more positive phases than negative phases of the WP teleconnection during EP-El Niño, which is consistent with the result reported in Dai and Tan (2016). CP-El Niño is favorable for the occurrence of negative phases of the WP teleconnection and it has no significant impact on the occurrence of positive phases of the WP teleconnection. This result is also supported by Fig. 9 which shows that a negative phase of the WP teleconnection appears in height anomalies at $200 \mathrm{hPa}$ during
CP-El Niño. As Figs. 6 and 7 indicate that height anomalies at $200 \mathrm{hPa}$ preceding long-lasting SSWs are related to positive phases of the WP and PNA teleconnections, the results in Fig. 10 suggest that EP-El Niño is favorable for the appearance of long-lasting minor and major SSWs, since it is favorable for both positive phases of the PNA and WP teleconnections; whereas, CP-El Niño would depress the occurrence of long-lasting minor and major SSWs, since it is more likely to generate a negative phase of the WP teleconnection.

Previous studies have found that SSWs are induced by the mean-flow forcing of planetary waves from the troposphere-primarily wavenumber 1 and wavenumber 2 (e.g., Matsuno, 1971; Holton, 1976). To obtain more information on the effects of Niño events on planetary waves, Fig. 11 shows the vertical component of Eliassen-Palm flux at $200 \mathrm{hPa}$ associated with wavenumber 1 and wavenumber 2 at middle to high latitudes during EP-El Niño and CP-El Niño. Compared with its climatology, the upward wave flux associated with wavenumber 1 is enhanced in the middle- and highlatitude upper troposphere during EP-El Niño. CP-El Niño has no significant impact on the wavenumber-1 upward flux at high latitudes. However, the wavenumber-1 upward flux 
(a)

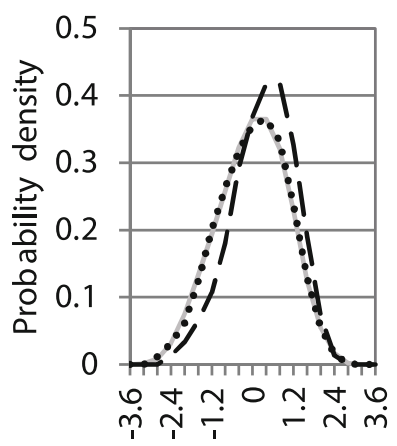

PNA Index (b)

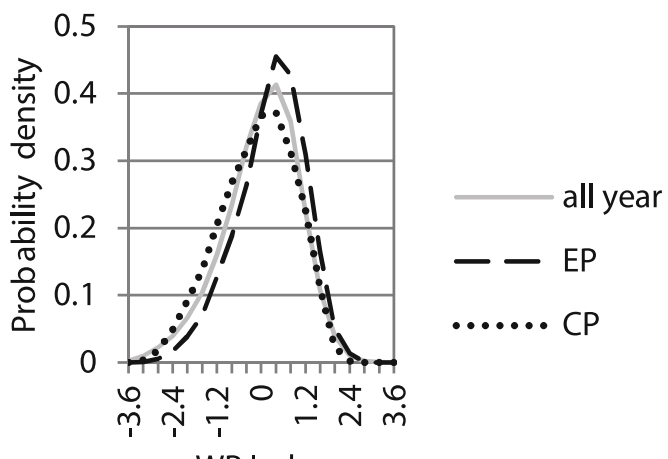

Fig. 10. The PDFs of the (a) PNA and (b) WP indices in winter (November-February) derived from the daily NCEP-NCAR reanalysis dataset during EP-El Niño (dashed lines) and CP-El Niño (dotted lines) winters, as listed in Table 1. The climatological PDFs of the PNA and WP indices are also plotted in (a) and (b), respectively (grey lines).

(a)

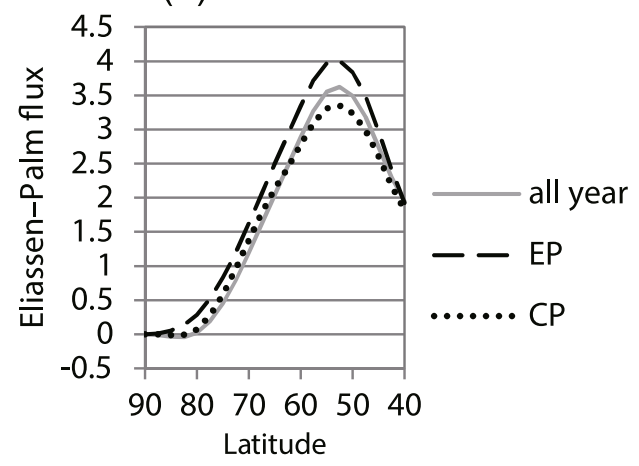

(c) (b)

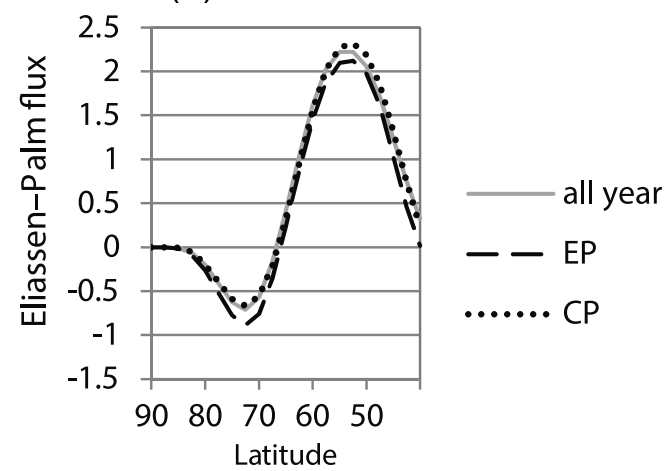

(d)
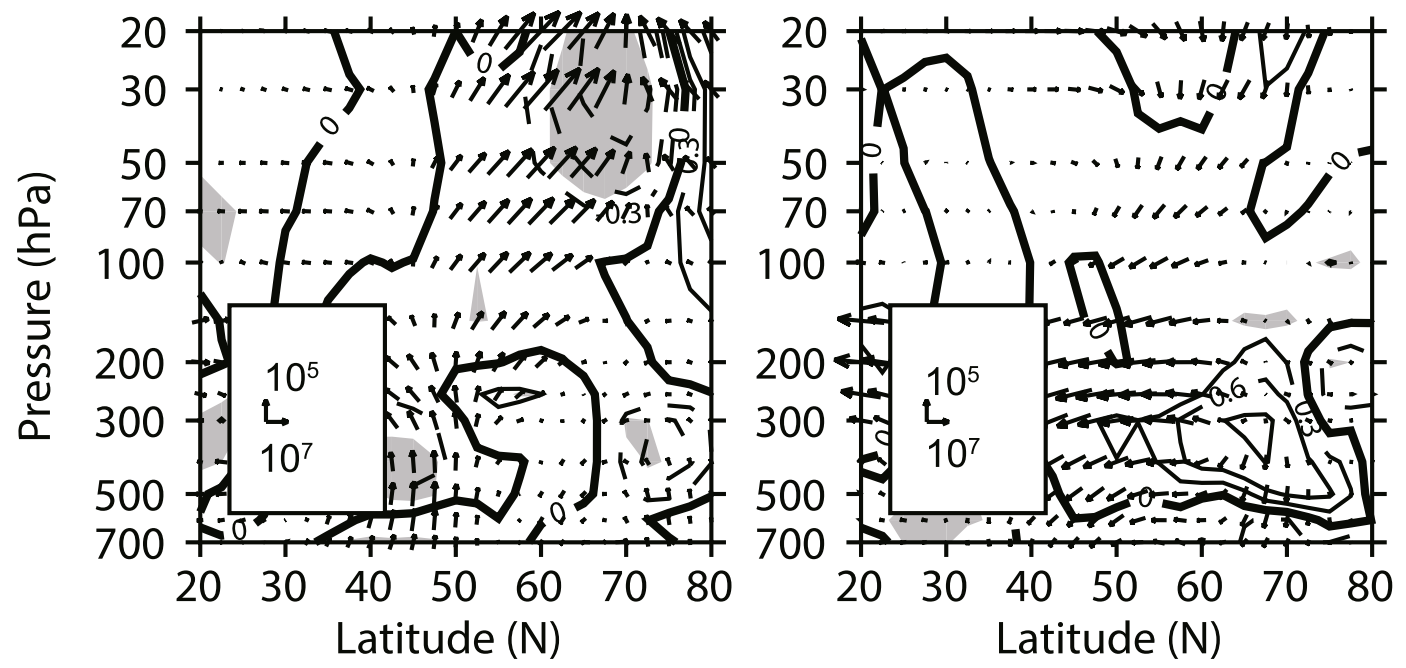

Fig. 11. Vertical component of Eliassen-Palm flux at $200 \mathrm{hPa}$ (divided by air density; units: $10^{5} \mathrm{~m}^{3} \mathrm{~s}^{-2}$ ) associated with (a) wavenumber 1 and (b) wavenumber 2 during EP-El Niño winters (dashed lines) and CP-El Niño winters (dotted lines), as listed in Table 1. The climatological means of the vertical component of EliassenPalm flux at $200 \mathrm{hPa}$ associated with wavenumber 1 and 2 are also plotted in (a) and (b), respectively (grey lines). (c, d) Differential Eliassen-Palm vectors and differences in Eliassen-Palm flux divergence (contours; units: $10^{-5} \mathrm{~m} \mathrm{~s}^{-2}$ ) associated with (c) wavenumber 1 and (d) wavenumber 2 between EP-El Niño and CP-El Niño. The differences in Eliassen-Palm flux divergence over gray-shaded regions are statistically significant at the $90 \%$ confidence level according to the Student's $t$-test. All the results shown here are derived from the NCEP-NCAR reanalysis dataset. 
in the middle-latitude upper troposphere is depressed during CP-El Niño relative to its climatology. The results here suggest that the upward wavenumber-1 wave flux in the extratropical upper troposphere during EP-El Niño is stronger than that during CP-El Niño. The upward wave flux associated with wavenumber 2 in the extratropical upper troposphere during CP-El Niño is not statistically different from that during EP-El Niño, although the upward wavenumber-2 wave flux during EP-El Niño is slightly smaller than that during CP-El Niño. Note that the magnitude of the upward wave flux changes associated with wavenumber 2 is smaller than that of wavenumber 1 , and the changes in the upward wave flux associated with wavenumber 1 dominate the variation of planetary wave fluxes in the upper troposphere.

The differential Eliassen-Palm flux vectors associated with wavenumber 1 and wavenumber 2 in the stratosphere between EP-El Niño and CP-El Niño are shown in Figs. 11c and $\mathrm{d}$, respectively, and the corresponding Eliassen-Palm flux divergence differences are over-plotted for reference. As expected, there are anomalous upward wavenumber-1 fluxes and anomalous downward wavenumber- 2 fluxes in the polar stratosphere during EP-El Niño, relative to that during CP-El Niño. The Eliassen-Palm flux divergence associated with wavenumber 1 in the subpolar stratosphere during EP-El Niño is smaller than that during CP-El Niño, which is consistent with the enhancement of the upward wave flux associated with wavenumber 1 in the middle- and high-latitude upper troposphere during EP-El Niño. As we know, a negative divergence of Eliassen-Palm flux corresponds to a decrease in the westerly wind and an increase in SSW strength. Therefore, Fig. 11 further confirms that SSWs tend to be stronger and last longer during EP-El Niño than during CP-El Niño.

\section{Summary and discussion}

This study uses NCEP-NCAR reanalysis data to investigate the different impact of EP-El Niño and CP-El Niño on the duration of SSWs. Our analysis reveals that the duration of both major and minor SSWs are shorter during CP-El Niño than during EP-El Niño, although the frequency of minor and major SSWs shows no notable difference between the two kinds of El Niño. It is also found that the GH anomalies preceding minor SSWs are related to the positive phase of the PNA teleconnection, while the height anomalies preceding major SSWs are related to the positive phase of the WP teleconnection. Furthermore, before the occurrence of major SSWs, the strength of both wavenumber 1 and wavenumber 2 is enhanced, while before the occurrence of minor SSWs, only the strength of wavenumber 1 is enhanced.

Composite analysis reveals that the $\mathrm{GH}$ anomalies in the high-latitude troposphere during EP-El Niño relate to positive phases of the PNA and WP teleconnections, while a negative-phase WP teleconnection is more likely to appear during CP-El Niño. As a result, the GH over Northeast Asia during EP-El Niño winter is lower than that during CP-El Niño winter, and the GH over North Canada during EP-El
Niño winter is higher than that during CP-El Niño winter. This contrast in the GH field between EP-El Niño and CP-El Niño implies that wavenumber 1 is strengthened during EPEl Niño and weakened during CP-El Niño. Consequently, the upward wave flux in the high-latitude stratosphere during EPEl Niño is larger than that during CP-El Niño. Enhanced upward wave flux in the high-latitude stratosphere during EP-El Niño leads to a weakened and prolonged polar vortex relative to that during CP-El Niño.

It is worth pointing out that the height anomalies preceding minor SSWs have a similar spatial pattern to the positive phase of the PNA teleconnection, and the height anomalies preceding major SSW bear a similarity with the positive phase of the WP teleconnection. Therefore, it seems that a strong positive phase of the PNA teleconnection can be regarded as a precursor for minor SSWs, while a strong positive phase of the WP teleconnection can serve as a precursor for major SSWs.

Acknowledgements. We are grateful to the agencies for providing the datasets used in this study. This work was supported by the National Natural Science Foundation of China (Grant Nos. 41225018 and 41575038).

Open Access. This article is distributed under the terms of the Creative Commons Attribution 4.0 International License (http://creativecommons.org/licenses/by/4.0/), which permits unrestricted use, distribution, and reproduction in any medium, provided you give appropriate credit to the original author(s) and the source, provide a link to the Creative Commons license, and indicate if changes were made.

\section{REFERENCES}

Andrews, D. G., J. R. Holton, and C. B. Leovy, 1987: Middle Atmosphere Dynamics. Academic Press, 489 pp.

Ashok, K., S. K. Behera, S. A. Rao, H. Y. Weng, and T. Yamagata, 2007: El Niño Modoki and its possible teleconnection. J. Geophys. Res., 112, C11007.

Baldwin, M. P., and T. J. Dunkerton, 2001: Stratospheric harbingers of anomalous weather regimes. Science, 294(5542), 581-584.

Bell, C. J., L. J. Gray, A. J. Charlton-Perez, M. M. Joshi, and A. A. Scaife, 2009: Stratospheric communication of El Niño teleconnections to European winter. J. Climate, 22(15), 40834096.

Bretherton, C. S., M. Widmann, V. P. Dymnikov, J. M. Wallace and I. Bladé, 1999: The effective number of spatial degrees of freedom of a time-varying field. J. Climate, 12, 1990-2009.

Butler, A. H., D. J. Seidel, S. C. Hardiman, N. Butchart, T. Birner, and A. Match, 2015: Defining sudden stratospheric warmings. Bull. Amer. Meteor. Soc., 96(11), 1913-1928.

Charlton, A. J., and L. M. Polvani, 2007: A new look at stratospheric sudden warmings. Part I: Climatology and modeling benchmarks. J. Climate, 20(3), 449-469.

Chen, W., M. Takahashi, and H.-F. Graf, 2003: Interannual variations of stationary planetary wave activity in the northern winter troposphere and stratosphere and their relations to NAM and SST. J. Geophys. Res., 108, doi: 10.1029/2003jd003834. 
Chiodi, A. M., and D. E. Harrison, 2013: El Niño impacts on seasonal U.S. atmospheric circulation, temperature, and precipitation anomalies: The OLR-event perspective. J. Climate, 26, 822-837, doi: 10.1175/jcli-d-12-00097.1.

Dai, Y., and B. K. Tan, 2016: The western Pacific pattern precursor of major stratospheric sudden warmings and the ENSO modulation. Environ. Res. Lett., 11, 124032, doi: 10.1088/17489326/aa538a.

Garfinkel, C. I., and D. L. Hartmann, 2008: Different ENSO teleconnections and their effects on the stratospheric polar vortex. J. Geophys. Res., 113, D18114, doi: 10.1029/2008JD009920.

Garfinkel, C. I., A. H. Butler, D. W. Waugh, M. M. Hurwitz, and L. M. Polvani, 2012: Why might stratospheric sudden warmings occur with similar frequency in El Niño and La Niña winters? J. Geophys. Res., 117, D19106.

Garfinkel, C. I., M. M. Hurwitz, D. W. Waugh, and A. H. Butler, 2013: Are the teleconnections of Central Pacific and Eastern Pacific El Niño distinct in boreal wintertime? Climate Dyn., 41(7-8), 1835-1852.

Graf, H.-F., and D. Zanchettin, 2012: Central Pacific El Niño, the "subtropical bridge," and Eurasian climate. J. Geophys. Res., 117, D01102.

Hegyi, B. M., and Y. Deng, 2011: A dynamical fingerprint of tropical Pacific sea surface temperatures on the decadal-scale variability of cool-season Arctic precipitation. J. Geophys. Res., 116, D20121, doi: 10.1029/2011JD016001.

Holton, J. R., 1976: A semi-spectral numerical model for wavemean flow interactions in the stratosphere: Application to sudden stratospheric warmings. J. Atmos. Sci., 33(8), 16391649.

Horel, J. D., and J. M. Wallace, 1981: Planetary-scale atmospheric phenomena associated with the Southern Oscillation. Mon. Wea. Rev, 109(4), 813-829.

Iza, M., and N. Calvo, 2015: Role of stratospheric sudden warmings on the response to Central Pacific El Niño. Geophys. Res. Lett., 42(7), 2482-2489.

Kao, H.-Y., and J.-Y. Yu, 2009: Contrasting eastern-Pacific and central-Pacific types of ENSO. J. Climate, 22(3), 615-632.

Lan, X. Q., W. Chen, and L. Wang, 2012: Quasi-stationary planetary wave-mean flow interactions in the Northern Hemisphere stratosphere and their responses to ENSO events. Science China Earth Sciences, 55, 405-417, doi: 10.1007/s11430011-4345-4.

Larkin, N. K., and D. E. Harrison, 2005: On the definition of El Niño and associated seasonal average U.S. weather anomalies. Geophys. Res. Lett., 32, L13705.

Li, Y., J. Li, and J. Feng, 2012: A teleconnection between the reduction of rainfall in Southwest Western Australia and North China. J. Climate, 25, 8444-8461.

Liebmann, B., and C. Smith, 1996: Description of a complete (interpolated) outgoing longwave radiation dataset. Bull. Amer. Meteor. Soc., 77, 1275-1277.

Limpasuvan, V., D. W. J. Thompson, and D. L. Hartmann, 2004: The life cycle of the Northern Hemisphere sudden stratospheric warmings. J. Climate, 17(13), 2584-2596.

Lu, C. H., and Y. H. Ding, 2015: Analysis of isentropic potential vorticities for the relationship between stratospheric anomalies and the cooling process in China. Science Bulletin, 60, 726-738, doi: 10.1007/s11434-015-0757-4.

Manzini, E., M. A. Giorgetta, M. Esch, L. Kornblueh, and E. Roeckner, 2006: The influence of sea surface temperatures on the northern winter stratosphere: Ensemble simulations with the MAECHAM5 model. J. Climate, 19(16), 3863-3881.

Matsuno, T., 1971: A dynamical model of the stratospheric sudden warming. J. Atmos. Sci., 28(8), 1479-1494.

Nakamura, H., K. Nishii, L. Wang, Y. J. Orsolini, and K. Takaya, 2016: Cold-air outbreaks over East Asia associated with blocking highs: Mechanisms and their interaction with the polar stratosphere. Dynamics and Predictability of LargeScale High-Impact Weather and Climate Events, J. P. Li, R. Swinbank, R. Grotjahn, and H. Volkert, Eds., Cambridge University Press, 225-235.

Nishii, K., H. Nakamura, and Y. J. Orsolini, 2010: Cooling of the wintertime Arctic stratosphere induced by the western Pacific teleconnection pattern. Geophys. Res. Lett., 37(13), L13805.

Rayner, N. A., D. E. Parker, E. B. Horton, C. K. Folland, L. V. Alexander, D. P. Rowell, E. C. Kent, and A. Kaplan, 2003: Global analyses of sea surface temperature, sea ice, and night marine air temperature since the late nineteenth century. $J$. Geophys. Res., 108, 4407, doi: 10.1029/2002JD002670.

Reichler, T., J. Kim, E. Manzini, and J. Kröger, 2012: A stratospheric connection to Atlantic climate variability. Nature Geosci., 5(11), 783-787.

Taguchi, M., and D. L. Hartmann, 2006: Increased occurrence of stratospheric sudden warmings during El Niño as simulated by WACCM. J. Climate, 19(3), 324-332.

Thompson, D. W. J., and J. M. Wallace, 2001: Regional climate impacts of the Northern Hemisphere annular mode. Science, 293(5527), 85-89.

Wallace, J. M., and D. S. Gutzler, 1981: Teleconnections in the geopotential height field during the Northern Hemisphere winter. Mon. Wea. Rev., 109(4), 784-812.

Wang, L., and W. Chen, 2010: Downward Arctic Oscillation signal associated with moderate weak stratospheric polar vortex and the cold December 2009. Geophys. Res. Lett., 37, L09707.

Xie, F., J. Li, W. Tian, J. Feng, and Y. Huo, 2012: Signals of El Niño Modoki in the tropical tropopause layer and stratosphere. Atmos. Chem. Phys., 12(11), 5259-5273.

Xie, F., J. P. Li, W. S. Tian, J. K. Zhang, and C. Sun, 2014: The relative impacts of El Niño Modoki, canonical El Niño, and QBO on tropical ozone changes since the 1980s. Environmental Research Letters, 9(6), 064020.

Yu, J.-Y., H.-Y. Kao, and T. Lee, 2010: Subtropics-related interannual sea surface temperature variability in the central equatorial Pacific. J. Climate, 23(11), 2869-2884.

Zhang, J. K., W. S. Tian, Z. W. Wang, F. Xie, and F. Y. Wang, 2015: The influence of ENSO on northern midlatitude ozone during the winter to spring transition. J. Climate, 28(12), 4774-4793.

Zhang, J. K., W. S. Tian, M. P. Chipperfield, F. Xie, and J. L. Huang, 2016: Persistent shift of the Arctic polar vortex towards the Eurasian continent in recent decades. Nature Clim. Change, 6(12), 1094-1099. 